\title{
Role of Proteinasis-Inhibitor Systems in Pathogenesis of Human Diseases \\ (Literature and Own Research Review)
}

\section{Divocha VA*}

Luhansk State Medical University, Rubezhnoe, Ukraine

*Corresponding Author: Divocha VA, Luhansk State Medical University, Rubezhnoe, Ukraine.

Received: September 23, 2019; Published: October 15, 2019

DOI: 10.31080/ASMI.2019.02.0398

\begin{abstract}
In the work presented the Author demonstrates the review of literature and own researches about the changes of enzyme-inhibitory system of a body under different diseases.
\end{abstract}

Keywords: Inhibitors; Proteinase

In recent years, much attention has been paid to the relationship between viruses (including influenza) and the host organism. One of these areas is the role of proteinase-inhibitor systems.

The system of proteins and their inhibitors is represented in the body by a large group of proteins. Proteolytic enzyme inhibitors act as regulators of the constant level of the corresponding enzymes in the body, being with them in a constant dynamic equilibrium. Disruption of this equilibrium is important for the development of pathological processes.

Human blood contains at least six inhibitors: alpha-2-antiplasmin, alpha-2-macroglobulin, alpha-1-antitrypsin, antithrombinIII, Cl - inactivator, inter-a-antitrypsin.

Thus, a decrease in antiplasmin activity was recorded in 6 $(16.7 \%)$ of the 36 patients with colon or stomach cancer between the ages of 50 and 76 [1].

The level alpha-2-antiplasmin in the blood plasma is significantly reduced in the pathological conditions of the liver, especially in cirrhosis of the liver [2].

In the case of a deficiency olpha-2-antiplasmin and an ant activator plasminogen-1 blood clots in the places of injury or operations dissolve prematurely, and the bleeding recurrences [3].
However, in some other pathologies, the level of a2-antiplasminin the blood plasma may not change. antiplasmine in patients with malignancies and donors did not differ, which indicates the persistence of protective fibrinolithic plasma activity in patients [4].

Alpha-2-macroglobulin (the main component of the fraction) is involved in the development of infectious and inflammatory reactions.

The predictive significance of determining the level of2-macroglobulin in viral and degenerative liver diseases has been established [5].

The onset of the disease was accompanied by a decrease in the level of2-macroglobulin and that patients with a sufficiently high level of this inhibitor had a better prognosis of the course of the disease [6]. High levels of2-macroglobulin are observed at 2-4 weeks of the disease in a third of patients with acute hepatitis B virus [7].

In the case of reniot, an increase in the level of 2-macroglobulin in the blood plasma and in the exudate of the sinuses was observed only in $15 \%$ of the patients [8]. 
In 103 patients with destructive pulmonary tuberculosis, several forms of serum were found to have several forms of 2-macroglobulin, the level of which varied during treatment [9]. The F-form of the inhibitor outpaced the decrease in the activity of the total q2-macroglobulin.Based on the results of the studies, the authors proposed to use the definition of the level of S-form alpha-2-macroglobulin as a predictive marker of relapse disease.

It has been shown that compared to serum and plasma levels of2-macroglobulin in healthy people, the level of this inhibitor increases in some neurological diseases [10], but does not change (regardless of duration of the disease) in multiple sclerosis [11].

In the rat experiment, it was shown that capsaicin-sensitive nerve damage was accompanied by an increase in the level of2macroglobulin 3 days after the injection [12].

Using a number of surgical procedures including castration and hepatectomy it has been shown that the increase in the level of 2-macroglobulin in the liver in response to inflammation is regulated, at least partially, by the testicle through testosterone. Partial hepatectomy caused a tenfold increase in mRNA levels and synthesis of2-macroglobulin in the liver, and castration caused a moderate increase in the level of 2-macroglobulin. Insufficient synthesis of 2-macroglobulin by the liver after castration can be correlated with preliminary injections of testosterone 6 days before the operation [13].

The hypothesis that the deficiency of 2-macroglobulin can contribute to the proteolytic destruction of arterial tissue and thus alpha2-macroglobulin is able pattoparticie indirectly in directly in the vascular disease has not been confirmed in studies in 80 patients with arterial aneurysms, as the level of this inhibitor was insignificantly different from that of donors [14].

A study of the level of alpha-2-macroglobulin in the serum of 170 men with long-term psoriasis cases showed a significant increase in this indicator in the acute phase of the disease and a decrease in the level to the indications of donors for long periods treatment that allowed the authors to offerq2-macroglobulin as a marker of treatment [15].

Fifty patients have a high level of alpha-2-macroglobulin in blood plasma [16], pleural and peritary exudates and ascite fluids of benign and malignant tumors [17].
Some authors suggest using the study of the level of2-macroglobulin as a marker of differential diagnosis of kidney disease in children. The syndrome, as opposed to simple glomerulonephritis, is characterized by a significant increase in the level of alpha2-macroglobulin in the urine, while in healthy children this inhibitor in the urine is absent [18].

Alpha-2-macroglobulin has also been proposed as a diagnostic criterion for rheumatoid arthritis, and monitoring concentrations of $_{2}$-macroglobulin with IgG in patients with rheumatoid arthritis can serve predictive criterion of the disease [19].

The third human blood inhibitor is alpha-1-antitrypsin. characterized by a periportal or more extensive inflammatory process in the liver, remains within the normal values [7].

Also, the level of serum alpha-1- antitrypsin remains within normal values inchronic viral hepatitis - a chronic liver disease caused by hepatitis B, C and D viruses, which develops 6 months after acute viral hepatitis [7].

Within the normalrange is the level of serum in patients with multiple sclerosis [11] and in adults with renitis [8].

Increased activity of serum alpha- ${ }_{1}$-antitrypsin is observed in $90 \%$ of cases in pulmonary tuberculosis and respiratory sarcoidosis [20], but in the silicosis of the lungs and in the serum of the electric welders, the content of1- antitrypsin remains within the norm [21].

There are some diseases, such as some types of liver pathology [22], pulmonary emphysema [23], chronic inflammatory arthritis, which are caused by hereditary deficiency of -antitrypsin or its gene mutations [24]. Hereditary deficiency of alpha- ${ }_{1}$-antitrypsin is also caused by the spread of chronic obstructive pneumonia [25].

For example, in the emphysema of smokers there is a decrease in the activity of serum alpha1 antitrypsin. to protect the lungs, the ratio of elastase and1-antitrypsin, which leads to lung damage, is disrupted. loss of lung elasticity. This causes the alveoli to collapse, which leads to their over-inflating and rupture. Smokers' emphysema is the result of disproportionate biochemical processes between elastase and alpha-1-antitrypsin, Alfa-1-antitrypsin is sufficient for healthy individuals to protect elastin, and therefore its pathological destruction does not occur [26]. 
Deficiency ofalpha-1-antitrypsin, which is observed in cirrhosis of the liver, developed after hepatitis $\mathrm{C}$ is caused by the homozygous state of allela ZZ, and pathological change of hepatocytes (without necrosis) - homozygous condition allele MM [27].

Individuals with asthmatic asthma syndrome also have a reduced content of1-antitrypsin.

In the experiment, in rats exposed to acetic lead inhalation, it was shown that under the influence of this substance there is a destruction of lung tissue, which is accompanied by a decrease in the level of1-antitrypsin and an increase in the activity of trypsinlike enzymes [28].

Increased activity of alpha-1- antitrypsin the serum is usually observed in chronic inflammatory processes such as rheumatoid arthritis. Caused by the predominance of M3 allele of this inhibitor.

The fourth inhibitor of human blood is antithrombin III. In most cases, with pathological conditions of the body, a decrease in antithrombin 3 is observed. So, in cancer patients, compared with healthy patients, a decrease in antithrombin level (1.4 times). At the same time, patients who did not receive preventive therapy were found to have decreased levels of antithrombin III (1.3 times for 3-6 days after surgery) in patients of the control group who did not receive preventive therapy [29]. Received low-molecular heparins (clean and tricenarian), the content of antithrombin III was practically no different from the baseline, which indicates the preservation of natural thrombin inhibitors and the protection of the body from thrombosis [30].

It has been shown that the main inhibitory activity in relation to plasmin in euglobulin precipitate has c1-antiactator.C1-anti-activator contains $43.7 \%$ carbohydrates, and sial icit is $14-15$ percent [31]. The fibrinolytic activity of the euglobulin plasma fraction depends in part on fluctuations in the content of $\mathrm{Cl}$-ant activator in the blood.

Another agent with an antifibrinolytic effect is a histidine-rich glycoprotein. It interferes with the binding of plasminogen with fibrin.

In plasminogen activation inhibitors (ant activators) in the ant activators of three immunological types
- Type 1:PA1-1-endothelial.Synthesized by endothelial cells and hepatocytes in culture, different hepatoma lines, melanoma cells and others, accumulates in platelet a-granules and plasma. Lessons at a rate of $106-10 \mathrm{M} / \mathrm{L}^{-1 \mathrm{z} 1}$ by forming with them an inactive and non-recurring complex. -4 hours at 37 degrees Celsius. Meanwhile, the semi-inactivation of the tissue activator,2-antiplasmin,occurs in 90to180 minutes.

- Type 2: PAI-2 - isolated from placenta and macrophages cultures of different origins.

- Type 3: Protease NEXIN from the cultural environment of fibroblasts. The molecule contains a heparin-binding area with high affinity. This proteinase reduces cell sensitivity to the miogenic action of thrombin, limits the activation of single-stranded lessons by exogenous proteases and inhibits double-stranded lessons-making. Fibroblasts have specific receptors for endocytosis and lysosomal degradation of this complex. Proteasa $\mathrm{N}$ is not defined in plasma. It has the same characteristics of reactions with thrombin, trypsin, tissue activator and lessons, so it can not be considered a pure ant activator.

Currently, the functions of in activators of proteinase of the human body and animals are not sufficiently studied. However, it is known that in normal plasma PAI-2 and protease $\mathrm{N}$ are not detected. About $60 \%$ of anti-active activity is on PAI-1, the remaining $40 \%$ - on a little-studied factor, denoted as RA, associated with protein. The participation of thrombin and protein $\mathrm{C}$, which bind PAI-1 to the complex (protein $\mathrm{C}$, thus has an antithrombin and profibrinolytic effect). The liver is responsible for removing active PAI from circulation. PAI is thought to be an acute phase protein. Its activity increases after large operations, severe injuries, myocardial infarction. After the introduction of corticosteroids, endotoxin (bact-LPS), H-1 PAI activity increases.

PAI activity (defined by immunological method) has been shown to gradually increase during pregnancy and in the third trimester the concentration of PAI-2 increases to 100 micrograms/ $\mathrm{ml}$, especially in the effects of pregnancy-related factors, and after childbirth returns to normal.

In patients with myocardial infarction there was an increase in PAI activity and a decrease in the content and activity of the tissue activator. OFTEN PAI activity increases in patients with venous thrombosis. Increased PAI in such patients in the preoperative period correlates with the threat of postoperative thrombosis. 
Increased PAI activity correlates with hyperlipoproteinemia and triglyceridemic. PAI increases in some severe patients with various disorders, but not with chronic renal failure, in which PAI activity in patients remains normal. Increased PAI activity is a nonspecific indicator of the severity of the process, but not a specific disease and predictive value this trait has only for patients with venous thrombosis.

In normal blood there are at least 2 pools of PAI activity: one is plasma, which is capable of rapid renewal and has wide concentration vibrations ( 0 to $1.3 \mathrm{~nm} / \mathrm{L}$ ); the other is platelet, which is localized in a-granules. During blood clotting, as a result of the release of PAI from platelets, the clot is protected from premature lysis. Due to PAI instability at 37 degrees Celsius and its inactivation by protein $\mathrm{C}$ and thrombin, PAI gradually disappears from the clot. With the subsequent penetration of plasminogen activators into the clot, the latter is licked.

In recent years, it has been established that protein-inhibitor systems of the body play an important role in the relationship between viruses and the human body. Viruses are intracellular infectious agents. The entire replicative cycle of the virus is carried out using the metabolic and genetic resources of cells. Therefore, the pathogenesis of viral infections, first of all, should be considered at the molecular and cellular levels (V.I. Pokrovsky, O.I. Kiselyov, 2002).

The system of proteins and inhibitors is represented in the body by a large group of proteins. It is known that inhibitors of proteolytic enzymes act as a constant regulator of the level of relevant enzymes in the body, are found with the latter in constant dynamic equilibrium. Disruption of the equilibrium between enzymes and inhibitors is important for the development of pathological processes.

Our studies have shown that in the lungs and serum of uninfected animals and chicken embryos, the levels of proteins and inhibitory proteinas activity are in balance, which is disrupted by infection with influenza A virus [32].

In the infectious process, there are several periods that are characterized by varying degrees of reproduction of the influenza virus, and different levels of proteinase and inhibitor activity.
The most profound changes occur in the first hours after contracting the influenza virus [33]. A similar phenomenon has been observed for Newcastle viruses and Aueski disease.

Thus, it can be assumed that in the first minutes after infection, observed changes in the enzyme-inhibitor balance in the animal's body appear to be related to the fact that influenza viruses contain both enzymes and their inhibitors. Further, the decrease in proteolytic activity is associated with the corresponding accumulation of proteinase inhibitor in the infected body. Influenza-infected cells appear to induce the appearance of an inhibitor, both in the lung tissue and in the serum. Thus, pulmonary tissue inhibitors are as if the first line of defense of the organ in the action of different strains of the influenza virus [34].

Other authors argue about the heterogeneity of serine protein inhibitors induced by influenza viruses. Thus, the amniotic-liquid inhibitor differed from trypsin inhibitors of 17-day amniotic fluid and ovomukoida in the protein of a chicken embryo [35]. Properties similar to the properties of subtylisin inhibitors described for ovoinhibitors and ovomacroglobulin of chicken embryos, black bean seeds and Streptomyces Subtilisin culture filter It's nota [36].

Proteinase inhibitors in the reproduction cycle of adenoviruses, vesicular stomatitis virus and simple herpes virus type- 2 [37] are virus-specific inhibitors that block critical metabolic stages of infected cells.

Our research suggests that virus-induced inhibitors detected in the first hours after infection block the activity of host cell proteinase, leaving influenza virus proteins protected from proteolytic hydrolysis. If the proteinase-inhibitor balance is disturbed, proteinase begins to break down hemagglutinin and there is an increase in the titer of the flu virus. Inject an additional inhibitor to block the proteinase activity.

Data from a number of virus models indicate that the mechanism of proteolytic activation has a general biological universal value [39]. The breakdown of glycoprotein, which cause the virus to enter the cell. Inhibitors block the process of splitting viral proteins by suppressing the activity of cellular enzymes. In the presence of cell protein inhibitors after one cycle of reproduction of the original virus with split proteins, viral offspring with unbroken, function- 
ally un active viral proteins are formed . Subsidiary virions are not able to initiate an infectious process due to the block of the early stages of the reproduction cycle - the absorption and penetration of the virus [40].

\section{Conclusion}

1. Inhibytors proteolytic enzymes act as regulators of the constant level of the corresponding enzymes in the body, being with them in a constant dynamic equilibrium.

2. Disruption of the enzyme-inhibitor system leads to the development of diseases such as: gastrointestinal cancer, cirrhosis of the liver, tuberculosis, tumors, glomerulonephritis, influenza, asthma, myocardial infarction.

3. Inhibitors block the process of splitting viral influenza proteins by suppressing cellular proteins.

4. A method of obtaining an antiviral drug against influenza, a trypsin-like protein inhibitor, has been developed and patented.

\section{Bibliography}

1. Vorobyov PA., et al. "Clinical and economic analysis of the preventive use of non-factional and low-molecular heparins in the surgical treatment of cancer patients. Post.1. Activity criteria". Journal of Modern Oncology 4.2 (2002): 99-109.

2. Aoki N and Yamanaka T. "The alpha2-plasmin inhibitor levels in liver diseases". Clinica Chimica Acta 1.84 (1978): 99-105.

3. Lampl L., et al. "Blood coagulation parameters as prognostic factors in multiple traumas: can clinical values be an early diagnostic aid?". Journal Zentralbl Chir 119.10 (1994): 683-689.

4. Somonova OV. "Diagnosis of hemostasis disorders and the principles of their correction in thrombotic complications in oncologists Abstract, Theses doctor of medical science Russian oncologists". N. N. Blokhin's Research Center RAMN Moscow (2008): 50.

5. Pedrazzini A and Wuhrmann F. "Prognostic importance of albumins and alpha-2-M globulins in viral and degenerative liver diseases". Epatologia 15.6 (1969): 389-392.

6. Van Gool J. "Profiles of acute-phase reactants and clinical significance of alpha 2-macroglobulin in acute hepatitis B". Inflammation 7.3 (1983): 277-289.

7. Meliconi R., et al. "Serum protease inhibitors in acute viral hepatitis". Ric Clinical Laboratory 17.1 (1987): 53-59.
8. Hamaguchi Y., et al. "Proteolytic activity and serum protease inhibitors in nasal secretions from adult patients with common colds". Rhinology 24.2 (1986): 125-132.

9. Esmedliaeva DS., et al. "The activity of alpha2-macroglobulin and its forms in patients with destructive pulmonary tuberculosis". Probl Tuberk Bolezn Legk 11 (2004): 40-43.

10. Rundle AT and Atkin J. "Serum alpha2-macroglobulin levels in tuberose sclerosis". Journal of Mental Deficiency Research 20.4 (1976): 231-236.

11. Bollengie F., et al. "Measles antibodies, anti-pro-teinase and plasminogen distribution in serum and plasma from patients affected with multiple sclerosis and patients affected with non-neurological diseases". Journal of Clinical Chemistry and Clinical Biochemistry 22.10 (1984): 653-659.

12. Tolochko ZS and Spiridonov VK. "Alternative changes of activity of alpha2-macroglobulin and alpha1-antitrypsin in rat blood following damage in capsaicin-sensitive nerves". Ross Fiziol Zh Im I M Sechenova 92.9 (2006): 1078-1084.

13. Lui WY., et al. "Alpha2-macroglobulin expression in the liver in response to inflammation is mediated by the testis". Journal of Endocrinology 185.3 (2005): 497-505.

14. Konrad C., et al. "Protease inhibitors in spontaneous cervical artery dissections". Stroke 36.1 (2005): 9-13.

15. Chodorowska G., et al. "C-reactive protein and alpha2-macroglobulin plasma activity in medium-severe and severe psoriasis". Journal of the European Academy of Dermatology and Venereology 18.2 (2004): 180-183.

16. Alexandrakis MG., et al. "Use of a variety of biological parameters in distinguishing cirrhotic from malignant ascites". International Journal of Biological Markers 16.1 (2001): 45-49.

17. Alexandrakis MG., et al. "Interleukin-6 and its relationships to acute phase proteins in serous effusion differentiation". Oncology Reports 8.2 (2001): 415-420.

18. Lubec G., et al. "Alpha-2-macroglobulin in children with glomerular diseases". Wiener klinische Wochenschrift 89.2 (1977): 49-53.

19. Zorina VN., et al. "Alpha-2-macroglobulin, its complexes with IgG and some factors of humoral immunity in rheumatoid arthritis Scientific-practical". Rheumatology 1 (2006): 22-27. 
20. Popov EV. "Clinical comparison of manifestations of systemic inflammation in patients with small forms of tuberculosis and sarcoidosis of the respiratory organs: asecond-Dis". PhD. State Institute of the Central Research Institute of the Russian Academy of Medical Sciences (2008): 21s.

21. Gola A., et al. "Alpha 1-antitrypsin level and the state of the respiratory tract in arc welders". Medycyna pracy 31.1 (1980): 41-44.

22. JB Otte., et al. "Liver transplantation in children". Chir Pediatr 26.5 (1985): 261-273.

23. Fagerhol MK. "The incidence of alpha-antitrypsin variants in chronic obstructive pulmonary disease". In: Mittman Ch. (ed.) Pulmonary emphysema and proteolysis". Academic Press London 4 (1972): 51-54.

24. Ulmer WT., et al. "Pulmonary emphysema. Clinical aspects and open questions". Fortschritte der Medizin 107.9 (1989): 201204.

25. Figueroa Casas JC., et al. "Chronic obstructive pulmonary disease”. Medicina (B Aires). 54.6 (1994): 671-696.

26. Jublik AY., et al. "Chronic obstructive pulmonary disease modern concept of pathogenesis, approaches to therapy". Clinical Immunology and Infectious Diseases 1.6 (2007): 27-35.

27. Hug G., et al. "Alpha 1-antitrypsin phenotype: transient cathodal shift in serum of infant girl with urinary cytomegalovirus and fatty liver". Pediatric Research 16.3 (1982):192-198.

28. Likholat EA., et al. "Proteolytic system in lungs upon inhalation exposure to low doses of lead salts". Ukrainskii Biokhimicheskii Zhurnal 72.6 (2000): 84-87.

29. Barkagan SS., et al. "The content of antithrombin 3 during the surgical treatment of patients with cancer of the gastrointestinal tract diseases". Problems of the pathology of the hemostatic system: etc. Science works. -Barnaul (2007):16-23.

30. Mamaev AN., et al. "Effectiveness of the anticoagulant system of protein $\mathrm{C}$ in patients with gastrointestinal cancers Problems of pathology of the hemostasis system: Sat. Science". works Barnaul (2007):145-148.

31. Sonowitz AS and Levitsky AP "Inhibitors of Proteolytic Enzymes in Medicine”. K Healthy (1985): 71.
32. Divocha VA. "Change of protease activity in the lungs of mice infected with influenza virus A VA Divocha, I.G. Grigorieva, A.G. Bukrinskaya Virology issues.5 (1999): 370-377.

33. Divocha VA. "Influenza virus and enzyme cells". Experimental and Clinical Medicine 2 (1999): 100-105.

34. Divocha VAIG., et al. "Change of protease activity in the lungs of mice infected with influenza virus A". Virology 5 (1990): 370377.

35. Matsushima K. "An undescribed trypsin inhibitory in egg white K. Matsushima”. Journals Science127 (1958): 1178-1179.

36. T Ikenaka., et al. "Amino acid sequence of an alkaline protease inhibitor (Streptomyces subtilisin inhibitor) from Streptomyces S - 3253". Journal of Biochemistry 76 (1974): 1191-1209.

37. Hill T., et al. "Herpes simplex virus type 1 and 2 induce shutoff of host protein synthesis by different mechanisms in Friend erythroleukemie cells". Journal of Virology 45 (1983): 241-250.

38. Divocha VA and Mikhelashvili MT. "Action inhibitor trypsin proteases for influenza infection in Experiment". Infectious Diseases 2 (2001): 35-39.

39. Sharp JL. "The current of 1-antitrypsin, a protease inhibitor in gastrointestinal disease J. L. Sharp". Gastroenterology. 70.4 (1976): 611-621.

40. Divocha VA. "Patent 23548 A Ukraine, MPK6 a $61 \mathrm{k} \mathrm{35/00.}$ Method of obtaining a tripsinlike protease inhibitor/hymen; applicant and patent holder hymen-No. 97052520; 30.05.97; convex. 02.06.98, Bul 4.

\section{Volume 2 Issue 11 November 2019 (C) All rights are reserved by Divocha VA.}

